\title{
Recent Trends in Incidence of Cerebral Hemorrhage and Infarction in Japan
}

\author{
A Report Based on Death Rate, Autopsy Case and \\ Prospective Study on Cerebrovascular Disease
}

Shibanosuke Katsuki, M.D. and Yasuo Hirota, M.D.

QINCE 1951, cerebrovasular disease (International Basic List No. 330-334) $\mathrm{N}$ has been the first cause of mortality in Japan. According to the Vital Statistics of Japan in 1962,"1 deaths from cerebrovascular disease (hereafter refered to as CVD) occurred in 161,288 persons, that is about 24 per cent of all deaths in this country. After the Second World War several reports ${ }^{2), 3}$ have shown an increasing trend in death from CVD, as a whole, in Japan. However, there has been few report dealing with the recent trends in incidence of 2 main types of CVD, i.e. cerebral hemorrhage and infarction, respectively.

In 1962, Goldberg and Kurland4) pointed out the highest incidence of cerebral hemorrhage in Japan among 33 countries in the world and they attributed this feature to some environmental or diagnostic factor rather than true ethenic factor in the Japanese. However, their study is based on the average annual age-adjusted death rate during the period from 1953 to 1957 and it may be possible to suppose that there has been some annual changes in incidence of these disorders in any country.

The purpose of this paper is to elucidate annual change of this feature of mortality from GVD in Japan by means of analysis of 3 kinds of sources; death rate, autopsy case and a prospective study in a selected community, called Hisayama-town, Fukuoka, Kyushu Island, Japan.

\section{Analysis of Death Rate ${ }^{5}$}

Vital Statistics Japan has been edited by Ministry of Welfare and Health of Japan and the classification criteria for cause of death has not been changed since 1950. It contains the number of deaths from each cause of death by sex and by every 5 year age group in each year in Japan.

Crude death rates and age-adjusted death rates from CVD and 2 major

From the Second Department of Internal Medicine (Director: Prof. S. Katsuki), Faculty of Medicine, Kyushu University, Fukuoka, Japan.

Received for publication September 25, 1965. 
types of them were calculated, using the population in 1961 as a standard, from 1951 to 1962 (Table I). As shown in Table I and Fig. 1, the age-adjusted death rate from all kinds of CVD was 148.4 per 100,000 population in 1951 and it has slightly increased to 166.5 in 1962 . The age-adjusted death rate from cerebral hemorrhage was 138.1 per 100,000 population in 1951 and it

Table I. Crude Death Rate and Age-adjusted Death Rate from Cerebrovascular Disease in Japan (1951-1962)

\begin{tabular}{|c|c|c|c|c|c|c|}
\hline \multirow{2}{*}{$\begin{array}{c}\text { Year } \\
1951\end{array}$} & \multicolumn{2}{|c|}{ GVD } & \multicolumn{2}{|c|}{ Cerebral Hemorrhage } & \multicolumn{2}{|c|}{$\begin{array}{c}\text { Cerebral Embolism } \\
\text { and Thrombosis }\end{array}$} \\
\hline & $125.2 *$ & $148.4^{* *}$ & $116.4 *$ & $138.1^{* *}$ & $4.0^{*}$ & $4.8 * *$ \\
\hline 1952 & 128.5 & 149.8 & 116.2 & 135.5 & 5.3 & 6.1 \\
\hline 1953 & 133.7 & 154.0 & 119.3 & 137.5 & 6.5 & 7.5 \\
\hline 1954 & 132.4 & 150.2 & 116.8 & 132.5 & 7.2 & 8.2 \\
\hline 1955 & 136.1 & 151.7 & 117.4 & 130.8 & 8.9 & 9.9 \\
\hline 1956 & 148.4 & 163.2 & 125.0 & 137.5 & 12.0 & 13.2 \\
\hline 1957 & 151.7 & 164.7 & 126.0 & 136.8 & 13.4 & 14.6 \\
\hline 1958 & 148.6 & 158.4 & 121.3 & 129.3 & 15.1 & 16.1 \\
\hline 1959 & 153.7 & 160.9 & 121.9 & 127.4 & 18.0 & 18.8 \\
\hline 1960 & 160.8 & 163.9 & 123.4 & 125.4 & 21.4 & 21.7 \\
\hline 1961 & 165.4 & 165.4 & 122.3 & 122.8 & 24.5 & 24.5 \\
\hline 1962 & 169.5 & 166.5 & 120.8 & 118.8 & 28.2 & 27.7 \\
\hline
\end{tabular}

* Grude Death Rate

** Age-Adjusted Death Rate (Standard-Population in 1961) Source: Vital Statistics Japan (1951-1962)

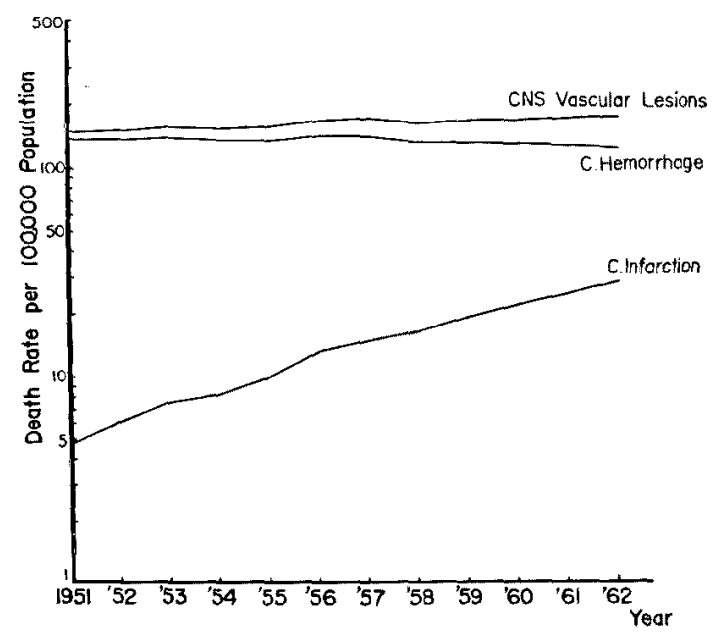

Fig. 1. Trends between 1951 and 1962 in age-adjusted death rate from CNS vascular lesions in Japan (Standard Year: 1961). 


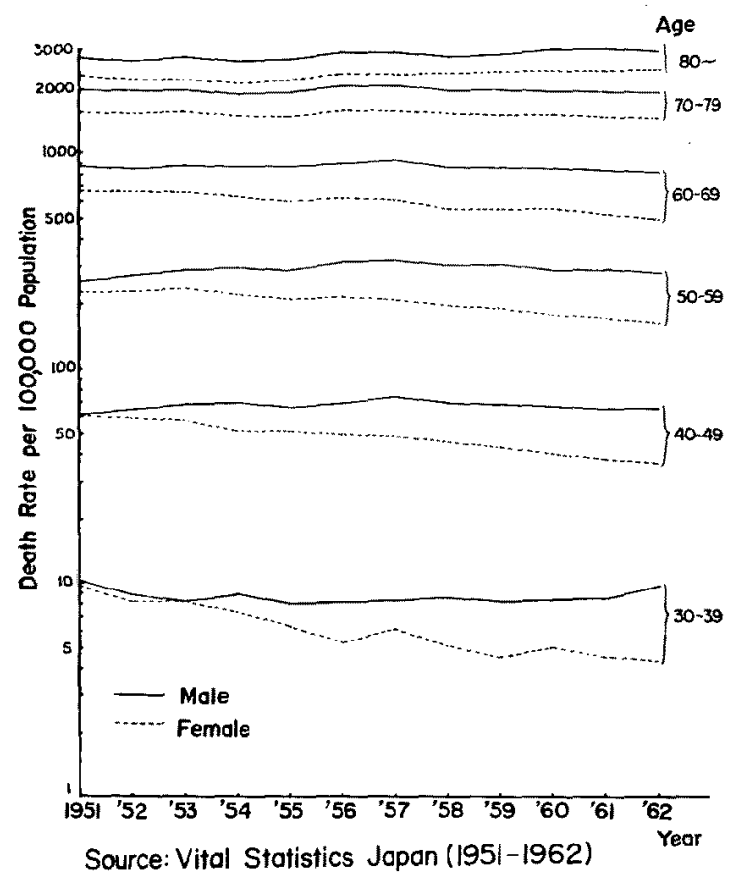

Fig. 2. Trends between 1951 and 1962 in death rate from cerebral hemorrhage (331) in Japan, by age and sex.

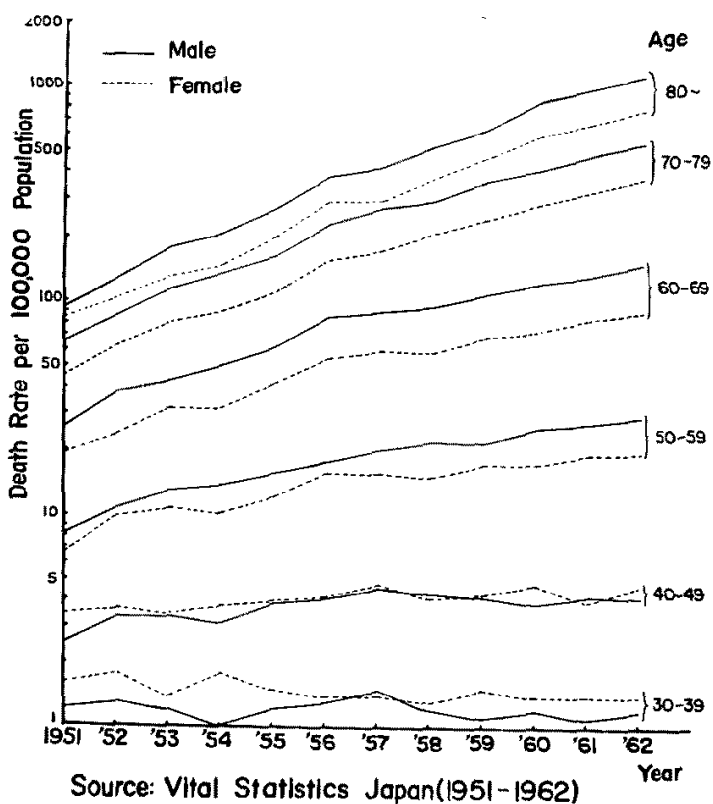

Fig. 3. Trends between 1951 and 1962 in death rate from cerebral infarction (332) in Japan, by age and sex. 
has decreased to 118.8 in 1962 . On the other hand, death rate from cerebral embolism and thrombosis was 4.8 per 100,000 population in 1951 and it has greatly increased up to 27.7 in 1962 . In other words, death due to cerebral infarction was about 5 time more common in 1962 than in 1951 in this country. The trends in the age-adjusted death rate from GVD in Japan from 1951 to 1962 were presented in Fig. 1.

By age and sex, the trends in the death rates from cerebral hemorrhage during these 11 years were shown in Fig. 2. In male, there were no remarkable changes in mortality from cerebral hemorrhage in any age group. In female, however, mortality from cerebral hemorrhage has decreascd during these 11 years, especially in the fourth, fifth and sixth decade.

The trends in the death rates from cerebral embolism and thrombosis by age and sex were shown in Fig. 3. In both sexes, the death rate from this disease has constantly increased, especially in older age groups. In the eighth and ninth decade, for instance, the mortality was nearly 10 times common in 1962 than in 1951.

\section{Analysis of Autopsy CAases ${ }^{5}$}

The Annual of Pathological Autopsy Cases of Japan ${ }^{6}$ is edited and published by the Japanese Pathological Society. Autopsy cases examined at major pathology departments in Japan are included and their age, sex, occupation, clinical diagnosis, main and secondary pathological diagnosis, and cause of death are described in these annuals. In this study, cases with hypertensive cerebral hemorrhage or massive cerebral hemorrhage described as main pathological diagnosis were classified as cerebral hemorrhage. Cases with atherosclerotic cerebral infarction or softening without any pathological findings attributable to cerebral embolism were classified as cerebral thrombosis.

The cases with secondary pathological diagnosis such as intracranial tumor or inflammatory process, meningitis, endocarditis, valvular heart disease, syphilitic changes of vascular system and leukemia or other blood disorders were excluded from this study. To avoid an inclusion of other kinds of disorders, only the cases aged 30 and over were analyzed. Legal autopsy cases were excluded, for they could not be considered to represent the general population. Moreover, to keep comparability in annual incidence only the cases from 76 pathology departments, which were presented in Volume I (1958) of the annual, were analyzed for the period of the following 5 years.

As shown in Table II, the number of autopsy cases in main departments of pathology in this country has increased year after year from 1958 to 1962 . Out of 29,795 autopsy cases for these 5 years, cerebral hemorrhage 
Table II. Frequency of Cerebral Hemorrhage and Thrombosis Among Autopsy Cases in Japan (over age of $30 \mathrm{yrs}$ )

\begin{tabular}{c|c|rc|rc|rc}
\hline \multirow{2}{*}{ Year } & $\begin{array}{c}\text { No. of } \\
\text { autopsy } \\
\text { cases }\end{array}$ & \multicolumn{2}{|c|}{ Hemorrhage } & \multicolumn{2}{|c|}{ Thrombosis } & \multicolumn{2}{|c}{ Hem. and Throm. } \\
\cline { 3 - 7 } & No. $\%$ & No. $\%$ & \multicolumn{2}{|c|}{ No. } & $\%$ \\
\hline 1958 & 5,205 & 112 & 2.2 & 79 & 1.5 & 11 & 0.2 \\
1959 & 5,437 & 99 & 1.8 & 91 & 1.7 & 10 & 0.2 \\
1960 & 6,026 & 145 & 2.4 & 110 & 1.8 & 6 & 0.1 \\
1961 & 6,403 & 128 & 2.0 & 144 & 2.2 & 12 & 0.2 \\
1962 & 6,724 & 164 & 2.4 & 170 & 2.5 & 10 & 0.1 \\
\hline Total & 29,795 & 648 & 2.2 & 594 & 2.0 & 49 & 0.2 \\
\hline
\end{tabular}

Source: Annual of Pathological Autopsy Cases in Japan.

was found in 648 or 2.2 per cent and cerebral thrombosis in 594 or 2.0 per cent and cases with both cerebral hemorrhage and thrombosis in 49 or 0.2 per cent. Annual incidence of cerebral hemorrhage was about 2 per cent and no marked change was found for these 5 ycars. On the contrary, annual incidence of cerebral thrombosis was 1.5 per cent in 1958 and it has constantly increased up to 2.5 per cent in 1962. Autopsy cases which showed both lesions such as hemorrhage and thrombosis was found in about 0.2 per cent in each year of these 5 years.

An age-specific tendency of incidence of cerebral hemorrhage and thrombosis was a possible cause of discrepancy in annual incidence, therefore an age-adjusting procedure was applied to the above mentioned data. The age distribution in 1962 was used as a standard. As shown in Fig. 4, the age-

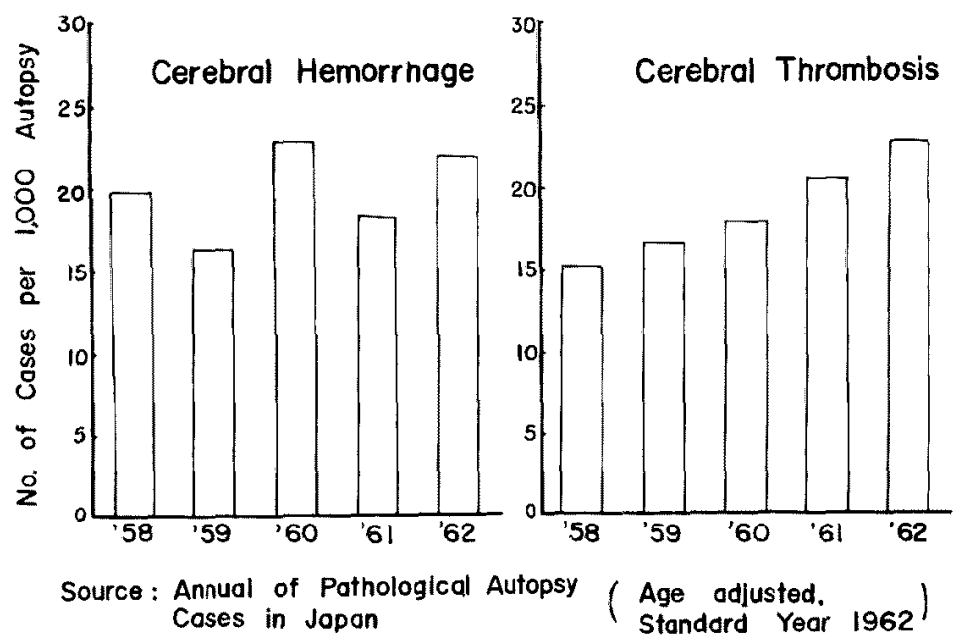

Fig. 4. Recent trends of incidence of cerebral hemorrhage and thrombosis among autopsy cases in Japan (over age of $30 \mathrm{yrs}$.). 
adjusted annual incidence of cerebral hemorrhage showed no definite trend for these 5 years. On the other hand, that of cerebral thrombosis has increased year after year and exceeded that of cerebral hemorrhage in 1962.

The trends in annual incidence of cerebral hemorrhage and thrombosis, by age group, based on autopsy cases were shown in Fig. 5 . In cases of cer-

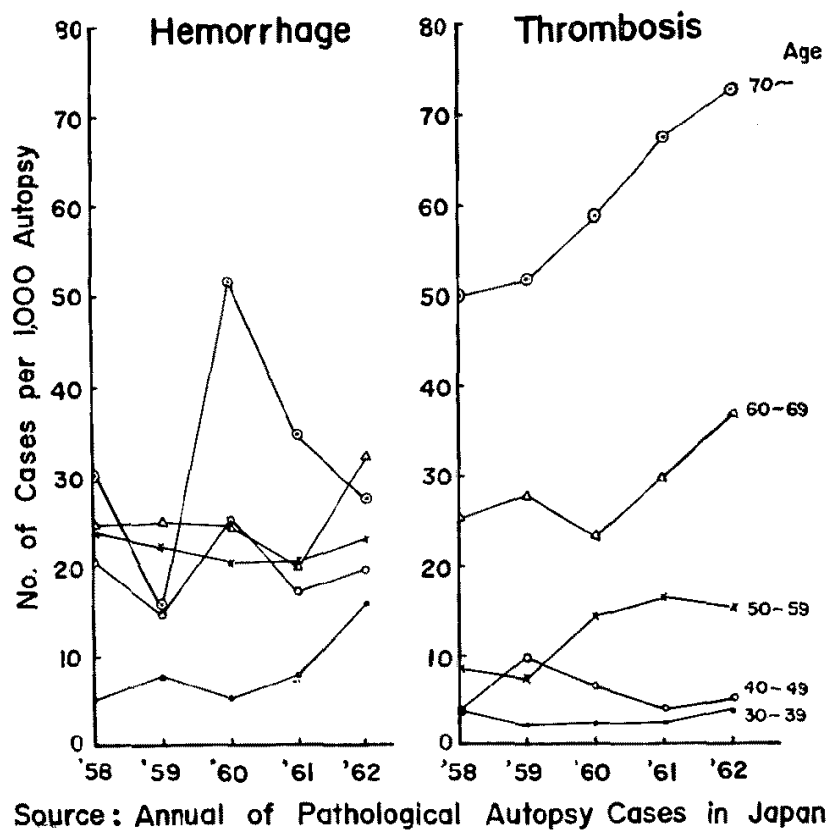

Fig. 5. Recent trends of incidence of cerebral hernorrhage and thrombosis among autopsy cases by age in Japan.

ebral hemorrhage, no definite trend was recognized in any age group. An increasing trend in incidence of cerebral thrombosis was evident in older age groups, especially in group aged 70 and over.

From the Prospective Study on CVD in Hisayama ${ }^{7), 81}$

The prospective study on CVD in Hisayama is in progress and a detailed report of the results will be described elsewhere. ${ }^{9)}$ At the present time, only a trend in annual incidence of CVD in this town is described briefly.

Out of 1,621 subjects, aged 40 and over without CVD, 38 have developed CVD newly during 3 years, from Nov. 1961 to Oct. 1964. Annual incidence of each type of CVD was shown in Table III. Cerebral hemorrhage occurred in 7 and cerebral thrombosis in 6 in 1962, the first year, 2 and 7 in 1963 and 1 and 9 in 1964, respectively. The differential diagnosis for type of CVD was based on the clinical observation by one of authors (Y.H.), using a consistent criteria for 3 years and, as a rule, the autopsy findings in death case. 
As to cerebral hemorrhage, for instance, the diagnosis was verified by autopsy in 3 of 6 death cases in the first year and in 2 of 2 deaths in the second year 1963, respectively. In cerebral thrombosis, the diagnosis was confirmed by autopsy in all death cases with only one exception in the first year.

Table III. Annual Incidence of CVD in Hisayama, Fukuoka, Japan

\begin{tabular}{|c|c|c|c|c|c|c|c|c|}
\hline Type of CVD & (Nov. 1 & $\begin{array}{l}\text { Year } \\
\text {-Oct. 1962) }\end{array}$ & (Nov. 1 & $\begin{array}{l}\text { Year } \\
\text { 2-Oct. 1963) }\end{array}$ & (Nov. ${ }^{3}$ & $\begin{array}{l}\text { Year } \\
\text {-Oct. 1964) }\end{array}$ & & Total \\
\hline $\begin{array}{l}\text { Cerebral } \\
\text { hemorrhage }\end{array}$ & 7 & $\begin{array}{l}\text { death } \\
6(3)\end{array}$ & 2 & $\begin{array}{l}\text { death } \\
2(2)\end{array}$ & 1 & $\stackrel{d}{0}^{\text {death }}$ & 10 & $\begin{array}{l}\text { denth } \\
8(5)\end{array}$ \\
\hline $\begin{array}{l}\text { Cerebral } \\
\text { thrombosis }\end{array}$ & 6 & $2(1)$ & 7 & $3(3)$ & 9 & $3(3)$ & 22 & $8(7)$ \\
\hline $\begin{array}{l}\text { Cerebral } \\
\text { embolism }\end{array}$ & 1 & $1(1)$ & 0 & & 0 & & & $1(1)$ \\
\hline $\begin{array}{l}\text { Subarachnoid } \\
\text { hemorrhage }\end{array}$ & 1 & $1(1)$ & 1 & $1(1)$ & 0 & & & $2(2)$ \\
\hline $\begin{array}{l}\text { Hemorrhage? } \\
\text { Thrombosis? }\end{array}$ & 3 & $3(0)$ & 0 & & 0 & & 3 & $3(0)$ \\
\hline Total & 18 & $13(6)$ & 10 & $6(6)$ & 10 & $3(3)$ & & $22(15)$ \\
\hline
\end{tabular}

As shown in Table III, it may be said that there has been a decreasing trend in annual incidence of cerebral hemorrhage and an increasing trend in cerebral thrombosis in this community.

The average age of onset of cerebral hemorrhage was 58 in 1962 and 67.5 in 1963. On the other hand, that of cerebral thrombosis was 68.2 in $1962,75.6$ in 1963 and 70.5 in 1964, respectively.

\section{Discussion}

Cause of death in Vital Statistics was generally based on death certificate, and necropsy has not been so popular that any reasonable reliability can not be put on differential diagnosis for CVD, not only in Japan but also in other countries. Therefore, changes in diagnostic habits of physicians and in medical concepts in recent years may affect the trend in mortality statistics on CVD. Mortality study, however, has a great advantage to get some suggestive leads. Autopsy cases derived from the Annual of Pathological Autopsy Cases in Japan, however, does not necessarily represent the general feature, because only the limited and selected cases of death undergo to post-mortem examination. From the epidemiological point of view the results obtained from our prospective study on GVD in Hisayama is quite important, because the all cases are completely followed and the diagnostic proccdure is based on our 
own clinical observation and autopsy. In this community we could observe a similar tendency of deaths due to cerebral hemorrhage and thrombosis that found in mortality statistics and autopsy reports of Japan.

Based on these 3 kinds of sources, it appears that cerebral hemorrhage has decreased slightly and cerebral thrombosis has increased greatly in the last decade in Japan. It may be negligible that these trends are the results of changes in diagnostic habit, since the definite increasing tendency of cerebral thrombosis is found in the autopsy cases.

In England and Wales, Yates ${ }^{10}$ has shown that there has been a change in the pattern of CVD and it is owing partly to a gradual fall in the number of deaths from cerebral hemorrhage and partly to an abrupt rise in the cases of cerebral infarction which started about 1947 and ceased about 1955. In the United States, ${ }^{11}$ ) death rates from cerebral embolism and thrombosis have increased and that from cerebral hemorrhage has decreased slightly since 1949. Wylie ${ }^{11)}$ has ascribed these trends in the United States to the changes in diagnostic habits of physicians, but no evidence has been presented in his report. In any cases, these findings seem to indicate that an increasing trend in death rate from cerebral infarction and a decreasing one in cerebral hemorrhage are the common features found in these countries, especially in recent decades.

During the last World War a decreasing trend in death from CVD was reported in Europe $^{12)}$ and Japan.,2), It was not shown which type of CVD had played the leading role of the reduction at that time. Some investigators ${ }^{4}$ have attributed the transient improvement in atherosclerotic disease to the considerable reduction in the consumption of eggs and dairy produce in many countries during the last war.

On the other hand, a relationship between hypertensive disease and GVD has been revealed by many evidences from the fields of epidemiology. ${ }^{71,8,14)}$ Smirk ${ }^{15), 16)}$ and associates have shown that the percentage of CVD in the treated patients with hypertension was about a half of that found in the patients who were not receiving treatment. Unfortunately, the type of CVD for which hypotensive drugs were most effective was not presented. Although many factors are presumed to be responsible for the changing pattern of CVD, there has been not enough report dealing with this problem to get a conclusion at present.

Our observation of the trend in incidence of CVD in Hisayama, which is now in progress, based upon almost all post-mortem examination seems to be most reliable from the epidemiological point of view, though its number of subjects is still rather small. 


\section{SUMMARY}

Trends in the incidence of cerebral hemorrhage and infarction in Japan were analyzed based on the 3 kinds of data obtained from death rate, autopsy case and our prospective study on CVD in a selected community, called Hisayama, Kyushu Island, Japan.

From the findings of mortality statistics it appears that cerebral hemorrhage has decreased slightly and, on the other hand, cerebral embolism and thrombosis has increased greatly for the recent 11 years.

Based on the main diagnosis of autopsy cases derived from various parts of this country, cerebral hemorrhage showed no definite change in annual incidence, while cerebral thrombosis had a steady increasing trend for the recent 5 years.

The prospective study on CVD in Hisayama showed a greatly decreasing trend in incidence of cerebral hemorrhage and a slightly increasing trend in incidence of cerebral thrombosis for the recent 3 years.

From these findings it can be supposed that there is some decreasing trend in cerebral hemorrhage and an apparent rising trend of cerebral thrombosis in Japan.

\section{REFERENGES}

1. Vital Statistics Japan: Koosei-Tookei-Kryookai (Tokyo), 1951-1962.

2. Watanabc, S.: J. Gerontology 14: 299, 1959.

3. i. Kin, G.: Tokyo Joshi Ikadaigaku Zasshi 27 : 144, 1957 (in Japanese). ii. Kin, G.: Tokyo Joshi Ikadaigaku Zasshi 27 : 232, 1957 (in Japanese).

4. Goldberg, L. D. and Kurland, L. T. : World Neurology $3: 444,1962$.

5. Hirota, Y.: Fukuoka Acta Medica 56: 1120, 1965.

6. Japanese Pathological Society: Annual of Pathological Autopsy Cases of Japan (Vol. 1-5), Kyorin-Shoin, Tokyo, 1958-1962 (in Japanese).

7. Katsuki, S., Hirota, Y. et al.: Jap. Heart J. $5: 12,1964$.

8. Katsuki, S., Omae, T., and Hirota, Y.: Kyushu J. Med. Sci. 15: 127, 1964.

9. Katsuki, S., Hirota, Y. et al.: in preparation.

10. Yates, P. O.: Lancet i : $65,1964$.

11. Wylie, C. M.: J. Chron. Dis. 14: 213, 1961.

12. Str $\phi \mathrm{m}, \mathrm{A}$. and Jensen, R. A.: Lancet i: $126,1951$.

13. Malmros, H.: Cited from Yates' report (9).

14. Berkson, D. M. and Stamler, J.: J. Atheroscler. Res. 5 : 189, 1965.

15. Hodge, J. V., McQueen, E. G., and Smirk, F. H. : Brit. Med. J. i : 1, 1961.

16. Smirk, H. and Hodge, J. V.: Brit. Med. J. ii : 1221, 1963. 